\section{Paracetamol, ibuprofen, or a combination of both drugs against knee pain: an excellent new randomised clinical trial answers old questions and suggests new therapeutic recommendations}

\author{
Kay Brune, ${ }^{1}$ Burkhard Hinz ${ }^{2}$
}

At first glance, the title of the article published by Doherty et al ${ }^{1}$ (see page 1534) does not promise much. Who would be interested in reading an investigation comparing two old well-known analgesics with each other or combinations of both? At a second glance, however, this cautious and excellent long-term study reveals many new and important findings which should be the basis for reconsideration of the treatment of musculoskeletal conditions with over-the-counter (OTC) analgesics. It may turn out that many of our widely-held beliefs and assumptions are wrong and that the recommendation for our patients needs to be changed.

Doherty et al investigate whether the combination of ibuprofen and paracetamol is better than the active components alone. To answer this question the authors compared the efficacy and safety of paracetamol and ibuprofen as well as that of two combinations of these drugs in community-derived patients aged $>40$ years with chronic knee pain. In a randomised, double-blind, four-arm parallel-group active controlled trial, the short-term (day 10) and long-term (week 13) benefits and side effects of four different therapeutic regimens were analysed:

1. ibuprofen (400 $\mathrm{mg}$ three times a day);

2. paracetamol (1000 $\mathrm{mg}$ three times a day);

'Department of Experimental and Clinical

Pharmacology and Toxicology, Friedrich-AlexanderUniversity Erlangen-Nuremberg, Erlangen, Germany

${ }^{2}$ Institute of Toxicology and Pharmacology, University of Rostock, Rostock, Germany

Correspondence to: Dr Kay Brune, Department of Experimental and Clinical Pharmacology and Toxicology, Friedrich-Alexander-University ErlangenNuremberg, Fahrstrasse 17, 91052 Erlangen, Germany; brune@pharmakologie.uni-erlangen.de of $\mathrm{OA}$ of the knee

1 If not stated otherwise: at day 10

${ }^{2}$ As measured with a $10 \mathrm{~cm}$ VAS

$3 * \mathrm{p}<0.05 ; * * \mathrm{p}<0.01$

${ }^{4}$ results as $\%$ of cohort
3. one fixed-dose combination tablet (ibuprofen $200 \mathrm{mg} /$ paracetamol $500 \mathrm{mg}$ (low-dose) three times a day);

4. two fixed-dose combination tablets (ibuprofen $400 \mathrm{mg} /$ paracetamol $1000 \mathrm{mg}$ (high-dose) three times a day).

In their four cohorts which included almost 900 participants the authors found that, at the first study end point (day 10), the high-dose combination was superior to paracetamol alone for pain relief, but was not superior to ibuprofen alone (table 1). At the second study end point (week 13), significantly more participants taking one or two combination tablets rated their treatment as excellent/ good compared with paracetamol alone; ibuprofen alone was better than paracetamol and not statistically inferior to the high-dose combination.

Adverse events were comparable between all groups, but numerically higher in the groups receiving combination tablets. Interestingly, the incidence of dyspepsia or diarrhoea was not lower in the paracetamol only group (as would have been expected by common wisdom). On the other hand, it is not surprising to find that the ibuprofen only group had no signs of liver toxicity in contrast to all three paracetamol groups. After 13 weeks a fall in haemoglobin (>1 g/ dl) occurred more frequently in patients taking a combination than in those on monotherapy with paracetamol or ibuprofen. The blood loss in the high-dose combination group was significantly higher than in all the other groups and reached clinically relevant proportions.

The authors conclude that the analgesic regimen of an ibuprofen/paracetamol combination confers modest short-term benefits for knee pain/osteoarthrosis and

Table: Effects of paracetamol (P) and ibuprofen (I) alone or in combination $(\mathrm{P}+\mathrm{I})$ in long term therapy

\begin{tabular}{|c|c|c|c|c|c|}
\hline Effects $^{1}$ & $P 3 \times 1 g / d$ & I $3 \times 0.4 \mathrm{~g} / \mathrm{d}$ & $\begin{array}{l}P(3 \times 0.5 g)+ \\
I(3 \times 0.2 g / d)\end{array}$ & $\begin{array}{l}P(3 \times 1 g)+ \\
I(3 \times 0.4 g / d)\end{array}$ & Comments \\
\hline $\begin{array}{l}\text { Pain reduction } \\
\text { (mm reduction from } \\
\text { baseline, day } 10)^{2}\end{array}$ & 10.1 & 13.3 & 12.8 & $15.0 * * 3$ vs $P$ & $\begin{array}{l}P \text { is inferior to } I \text { or } \\
P+I\end{array}$ \\
\hline $\begin{array}{l}\text { Patients' global } \\
\text { assessment } \\
\text { (\% rating good or } \\
\text { excellent) }\end{array}$ & 38.1 & $54.6{ }^{*}$ vs P & 53.9 & $61.4{ }^{* *}$ vs $P$ & $\begin{array}{l}\text { combinations are not } \\
\text { superior to I }\end{array}$ \\
\hline $\begin{array}{l}\text { AEs, any drug } \\
\text { related }^{4,5}\end{array}$ & 27.5 & $21.0 \mathrm{p}<?$ & 28.8 & 30.8 & $\begin{array}{l}\mathrm{P} \text { alone or in combination } \\
\text { causes more AEs than I }\end{array}$ \\
\hline Dyspepsia (day 10$)^{4}$ & 5.0 & 6.3 & 11.7 & 6.3 & \multirow{2}{*}{$\begin{array}{l}\text { P alone or in combination } \\
\text { causes as many dyspepsia } \\
\text { or diarrhea as I }\end{array}$} \\
\hline Diarrhoea (day 10$)^{4}$ & 4.5 & 1.8 & 1.8 & 6.7 & \\
\hline $\operatorname{ALAT}^{3,4,5}$ & 3.1 & 0.0 & 1.0 & 3.4 & \multirow{2}{*}{$\begin{array}{l}\mathrm{P} \text { alone or in combination } \\
\text { causes impairment of liver } \\
\text { function }\end{array}$} \\
\hline$\gamma \mathrm{GT}(>2 x \text { normal limit })^{4}$ & 6.7 & 0.5 & 3.5 & 3.4 & \\
\hline $\begin{array}{l}\mathrm{Hb} \downarrow(>1 \mathrm{~g} \text { from } \\
\text { baseline, day } 10)^{4,5}\end{array}$ & 7.3 & 11.3 & 10.8 & $\begin{array}{l}17.5 \\
p<0.01 * *\end{array}$ & $\begin{array}{l}\mathrm{P} \text { and I cause blood loss; } \\
\mathrm{P}+\mathrm{I} \text { (high dose) enhance } \\
\text { blood loss }\end{array}$ \\
\hline $\begin{array}{l}>1 \mathrm{~g} \text { at study } \\
\text { endpoint } \mathrm{t}^{4,5}\end{array}$ & 20.3 & 19.6 & 24.1 & $\begin{array}{l}38.4 \\
p<0.01 * *\end{array}$ & $\begin{array}{l}\text { Blood loss due to } \\
\mathrm{P}+\text { I reaches clinically } \\
\text { relevant proportions with } \\
\text { time }\end{array}$ \\
\hline $\begin{array}{l}>2 \mathrm{~g} \text { at study } \\
\text { endpoint }{ }^{4,5}\end{array}$ & 0.9 & 0.9 & 1.8 & $6.9 p<?$ & $\begin{array}{l}\text { The effect of } P+I \text { appears } \\
\text { more than additive }(p<?)\end{array}$ \\
\hline
\end{tabular}

${ }^{5}$ Alanine transferase (alanine transaminase; $\%$ of patients showing $>2 x$ normal limit) 
that patients taking paracetamol ( $3 \mathrm{~g} /$ day) may have similar degrees of blood loss to those taking ibuprofen (1200 mg/day). In addition, patients on the high-dose combination appear to have a higher blood loss than those on ibuprofen alone.

However, there is more to be considered. The important results are summarised in table 1.

Concerning pain relief, the data clearly show that (1) paracetamol $1000 \mathrm{mg}$ three times a day does not provide satisfactory pain relief in the majority of patients; (2) neither the high- nor the low-dose combination of ibuprofen with paracetamol is superior to ibuprofen alone; and (3) ibuprofen alone or combined with paracetamol is superior to paracetamol alone.

The results described here should be used as an argument to avoid the combination of different cyclo-oxygenase (COX) inhibitors. Interestingly, several studies published during the past few years have shown that paracetamol is an inhibitor of peripheral COX enzymes. ${ }^{2-4}$ In one of these studies preferential COX-2 inhibition was reported in volunteers receiving $1000 \mathrm{mg}$ paracetamol. ${ }^{3}$ However, this effect was short-lived and did not result in the prolonged $80 \%$ inhibition of COX-2 that is necessary for pain relief, ${ }^{5}$ thus explaining the only moderate analgesic action of paracetamol compared with traditional non-steroidal anti-inflammatory drugs (NSAIDs). More relevant, however, these data strongly imply that overdosing two COX-2 inhibitors-in this case ibuprofen and paracetamol-is not expected to enhance analgesia given that a plateau is reached with a sufficient dose of either drug. In the present case, sufficient COX-2 inhibition had most likely already been achieved with ibuprofen $400 \mathrm{mg}$ three times a day.

More important (although not statistically significant) are the reported unwanted drug effects: the proportion of drug-related adverse effects is actually higher in the treatment groups exposed to paracetamol/ibuprofen combinations. Dyspepsia and diarrhoea were observed with paracetamol and all combinations at least as frequently as dyspepsia following ibuprofen alone. Signs of liver toxicity (increased alanine aminotransferase and $\gamma$-glutamyltransferase) were seen in all groups receiving paracetamol. Paracetamol administration accompanies (causes?) and enhances blood loss. Remarkably, the blood loss increases with time and the dose of paracetamol, with or without ibuprofen.

The finding that patients on the highdose combination lost more blood than those on ibuprofen alone is in agreement with a previously published retrospective cohort study of older patients who reported an increased risk of gastrointestinal bleeding with a combination of a traditional NSAID and paracetamol compared with either agent alone. ${ }^{6}$ The authors explained this finding by the additional COX-1 inhibition by paracetamol, which is plausible in view of data showing that paracetamol augments the inhibitory action of diclofenac on platelet aggregation. ${ }^{7}$

In conclusion, it is very gratifying to see that this study which investigates the therapeutic value of combining two nonaspirin COX inhibitors is published at all. We doubt that another study of comparable size, cost and quality will be performed in the near future, certainly not supported by a drug company. The results indicate that we should reconsider using a combination of analgesics and also the use of paracetamol alone, as it is not sufficiently effective yet causes many unwanted effects including dyspepsia, diarrhoea, and gastrointestinal blood loss. In line with this notion, studies published during the past few years have shown that paracetamol increases blood pressure when taken for short or prolonged periods ${ }^{8-10}$ and augments the risk of major cardiovascular events when administered at high frequency or dose. ${ }^{11}$ Moreover, there is no mechanistic justification for the combination of paracetamol with another COX-2 inhibitor: the enzyme responsible for the formation of algesic prostaglandin $\mathrm{E}_{2}$ can only be blocked once. Two blockers cannot achieve more effects than one blocker! The analgesic action increases only marginally (if at all), but the unwanted drug effects increase substantially.

On the basis of this study, one wonders why combinations of analgesics of the type described and investigated here should remain on the OTC market. Obviously there is no scientific evidence that either claim-higher efficacy and/ or less toxicity - can be substantiatedrather, the contrary is true.

Acknowledgment KB is Doerenkamp-Professor supported by the Hertie Foundation.

\section{Competing interests None.}

Contributors $\mathrm{KB}$ developed the concept of this editorial and compiled the table. BH wrote parts of the article and added to the literature.

Provenance and peer review Commissioned; externally peer reviewed.

Accepted 7 July 2011

Ann Rheum Dis 2011;70:1521-1522.

doi:10.1136/annrheumdis-2011-200242

\section{REFERENCES}

1. Michael Doherty, Chris Hawkey, Michael Goulder, et al. A randomised controlled trial of ibuprofen, paracetamol or a combination tablet of ibuprofen/ paracetamol in community-derived people with knee pain. Ann Rheum Dis 2011;70:1534-41.

2. Boutaud 0, Aronoff DM, Richardson JH, et al. Determinants of the cellular specificity of acetaminophen as an inhibitor of prostaglandin H(2) synthases. Proc Natl Acad Sci USA 2002;99:7130-5.

3. Hinz B, Cheremina 0, Brune K. Acetaminophen (paracetamol) is a selective cyclooxygenase-2 inhibitor in man. FASEB J 2008;22:383-90.

4. Lee YS, Kim H, Brahim JS, et al. Acetaminophen selectively suppresses peripheral prostaglandin E2 release and increases COX-2 gene expression in a clinical model of acute inflammation. Pain 2007;129:279-86.

5. Huntjens DR, Danhof M, Della Pasqua OE. Pharmacokinetic-pharmacodynamic correlations and biomarkers in the development of COX-2 inhibitors. Rheumatology (Oxford) 2005;44:846-59.

6. Rahme E, Barkun A, Nedjar H, et al Hospitalizations for upper and lower Gl events associated with traditional NSAIDs and acetaminophen among the elderly in Quebec, Canada. Am J Gastroenterol 2008;103:872-82.

7. Munsterhjelm E, Niemi TT, Ylikorkala 0 , et al. Characterization of inhibition of platelet function by paracetamol and its interaction with diclofenac in vitro. Acta Anaesthesiol Scand 2005;49:840-6.

8. Sudano I, Flammer AJ, Périat D, et al. Acetaminophen increases blood pressure in patients with coronary artery disease. Circulation 2010;122:1789-96.

9. Forman JP, Stampfer MJ, Curhan GC. Nonnarcotic analgesic dose and risk of incident hypertension in US women. Hypertension 2005; $46: 500-7$

10. White WB, Campbell P. Blood pressure destabilization on nonsteroidal antiinflammatory agents: acetaminophen exposed? Circulation 2010;122:1779-81.

11. Chan AT, Manson JE, Albert CM, et al. Nonsteroidal antiinflammatory drugs, acetaminophen, and the risk of cardiovascular events. Circulation 2006;113:1578-87. 